\title{
El gobierno de
} coalición en México:

un instrumento para los partidos políticos y el presidencialismo*

/ The coalition

government in Mexico: an instrument

for political parties and the nature of the presidency

\footnotetext{
* Artículo de investigación. Recibido: 27 de noviembre de 2017. Aceptado: 7 de junio de 2018. Tla-MelauA, revista de Ciencias Sociales. Facultad de Derecho y Ciencias Sociales. Benemérita Universidad Autónoma de Puebla, México / E-Issn: 2594-0716 / Nueva Época, año 12, núm. 45, octubre 2018-marzo 2019, pp. 30-51.
} 
Alberto Escamilla Cadena*

René López De La Torre**

RESUMEN

El presente artículo versa sobre el gobierno de coalición en México. Esta modalidad fue aprobada dentro del conjunto de reformas político-electorales que se llevaron a cabo en el año 2014. Se trata de un nuevo instrumento que tendrán los presidentes mexicanos a partir de 2018, para enfrentar los dilemas del gobierno sin mayoría y así poder construir una gobernabilidad democrática. Si bien la medida es opcional, su conformación debe apegarse a una serie de modalidades jurídicas, establecidas en el artículo 89 constitucional.

El gobierno de coalición podría resolver problemas derivados de la falta de mayorías congresionales, aunque también implica riesgos de polarización al interior de la coalición gobernante. Este trabajo analiza la forma en que quedó configurada legalmente esta figura, así como los retos y las modificaciones que enfrentaría el sistema presidencial mexicano, en caso de implementarse.

\section{PALABRAS CLAVE} Gobiernos de coalición, México, presidency. presidencialismo.
A B S TRACT

This article deals with the coalition government in Mexico. This modality was approved within the set of political and electoral reforms that were carried out in 2014. A fact that Mexican presidents will have to encounter starting in 2018, this will lead to the dilemma of how to government without a majority. The Presidency will have to build a democratic governability. Although the measure is optional, its conformation must adhere to a series of legal modalities, established in Article 89 of the National Constitution.

The coalition government would need to solve problems derived from the lack of a congressional majority. This leads to risks of polarization within the governing coalition. This research paper analyzes the way it was legally configured, as well as the challenges and modifications that the Mexican presidential system would have to face, if implemented.

KEYWORDS

Coalition governments, Mexico,

\footnotetext{
* Profesor investigador en la Universidad Autónoma Metropolitana, Unidad Iztapalapa, México. (aescamillac@hotmail.com) orcid.org/0000-0003-4501-9381

**Asistente de investigación del Departamento de Sociología de la Universidad Autónoma Metropolitana, Unidad Iztapalapa, México. (rldlt1994@hotmail.com) orcid.org/0000-0001-8901-7658
} 


\section{INTRODUCCIÓN}

$\mathrm{Al}$ inicio del mandato de Enrique Peña Nieto, tuvo lugar un acuerdo entre partidos políticos, denominado el Pacto por México. Dentro de la agenda de temas que lo conformaban, se procesó una reforma político-electoral durante el año 2014. En aquel momento, el Poder Legislativo modificó el artículo 89 constitucional otorgando nuevas facultades al presidente de la república. Así, se abre la posibilidad de formar un gobierno compartido, al tiempo que se introdujeron controles en sus poderes de nombramiento. Este cambio contempla la posibilidad de que el presidente que gane la elección de 2018 pueda formar un gobierno de coalición.

Lo anterior tendría algunas consecuencias en el funcionamiento del presidencialismo mexicano, pues se introdujeron algunos mecanismos que son típicos de los sistemas parlamentarios. No obstante, esta figura ya se ha utilizado en varios países de la región latinoamericana, con los más diversos resultados. ${ }^{1}$ En México, a partir de 2018, año en que se celebrarán elecciones para renovar al titular del ejecutivo, podría concretarse esta modalidad.

En primer lugar, el gobierno de coalición fue justificado por los legisladores como un instrumento necesario, dado que es poco probable que un mandatario obtenga una mayoría de su partido en las dos cámaras del Poder Legislativo. En segundo lugar, esta figura quedó asentada en la ley como "opcional". Es una prerrogativa que el Ejecutivo puede utilizar para formar un gobierno que incluya a la oposición. No obstante, también cuenta con la facultad para disolverlo, cuando lo considere conveniente.

Este cambio constitucional podría introducir tres nuevos elementos en el proceso de gobierno: a) la construcción de una coalición entre partidos políticos al interior del congreso, con la finalidad de alcanzar las mayorías requeridas para sancionar leyes y reformas; $b$ ) la apertura de algunas carteras de gobierno hacia algunas de las figuras de los partidos políticos de oposición y c) la aprobación de la mayoría de los titulares del gabinete por parte del Poder Legislativo.

\footnotetext{
${ }^{1}$ Lanzaro, Jorge, "Tipos de presidencialismo y modos de gobierno en América Latina", en Jorge Lanzaro
} (comp.), Tipos de presidencialismo y coaliciones politicas en América Latina, Buenos Aires, Clacso, 2001, pp. 15-40. 
Si el próximo mandatario opta por formalizar un gobierno de coalición, se modificarían algunos procedimientos que se han mantenido inalterados durante décadas en el presidencialismo mexicano, como son sus facultades de nombramiento. Asimismo, se pondría fin al gobierno compuesto por un solo partido. La reforma al artículo 89 constitucional de 2014 continúa con la ruta iniciada, desde hace más de veinte años, en el presidencialismo mexicano: la tendencia a limitar sus poderes, así como la intención de vigilar y controlar sus acciones.

Considerando que el Legislativo tiene una conformación pluralista desde hace años, la reforma constitucional al artículo 89 ahora abre la opción para que el gabinete tenga una conformación bipartidista o multipartidista. Mientras que el primero tomaría decisiones y elaboraría leyes, el segundo las ejecutaría, con la particularidad de que ni uno ni otro estarían bajo el control de un mismo partido. Un diseño de esta naturaleza cambiaría algunos métodos, reglas y procedimientos del presidencialismo mexicano.

La conformación de un gobierno de coalición en otros países de la región latinoamericana ha tenido resultados contrastantes; por un lado, la inclusión de la oposición partidista ha producido, en algunos momentos, una toma de decisiones consensuada. Por otro lado, también ha producido fuertes enfrentamientos entre poderes, lo cual ha afectado negativamente la gobernabilidad. Este instrumento no es una garantía de que habrá un entendimiento entre los actores políticos; más bien, es una alternativa que puede posibilitar la cooperación entre los poderes públicos y los partidos políticos en el proceso legislativo y de gobierno.

El objetivo de este trabajo es conocer las modalidades con las que operaría el gobierno de coalición en México, después de la reforma al artículo 89 constitucional de 2014. La pregunta que se desprende de este análisis busca indagar cuáles serían las consecuencias políticas para el presidencialismo mexicano en caso de que se estableciera la figura del gobierno de coalición en un futuro.

La reforma abre la posibilidad de terminar con el juego de suma cero de las elecciones presidenciales en donde "el ganador se lo lleva todo". ${ }^{2}$ En la primera parte de este capítulo, se exponen algunos elementos teóricos relacionados con el presidencialismo y las coaliciones políticas; en la segunda, se abordan algunos aspectos de las coaliciones parlamentarias en México; mientras que, en el tercero, se abordan las modalidades del gobierno de coalición. Específicamente, se estudia la apertura del gabinete hacia la oposición y la ratificación de sus titulares por parte del congreso.

\footnotetext{
${ }^{2}$ Linz, Juan, "Democracia presidencial o parlamentaria ¿qué diferencia implica?”, en Juan Linz y Arturo Valenzuela (comps.), Las crisis del presidencialismo, tomo 1, Perspectivas comparadas, Madrid, Ariel, 1994, p. 46.
} 


\section{PRESIDENCIALISMO Y COALICIONES POLÍTICAS}

Los sistemas presidencialistas han enfrentado una serie de retos durante la fase de consolidación democrática (gobernabilidad, rendición de cuentas, corrupción, administración de justicia, entre otros) que no siempre se han resuelto satisfactoriamente. Frente a estos problemas, hay una serie de propuestas que sugieren la necesidad de renovar los sistemas presidencialistas.

Dieter Nohlen ha utilizado el concepto de adecuación funcional del presidencialismo; Diego Valadés ha propuesto la racionalización del poder presidencial; Jorge Carpizo hablaba de la parlamentarización del presidencialismo; mientras que Giovanni Sartori apuntaba sobre el presidencialismo intermitente. Estas nociones coinciden con la idea de imponer límites y controles a los poderes y las acciones del ejecutivo.

El concepto que puede adecuarse de mejor manera al estudio de los gobiernos de coalición en los presidencialismos es el de Diego Valadés: la racionalización del poder presidencial. Esta modalidad implica que se introducen elementos propios de los sistemas parlamentarios, como la ratificación de algunos nombramientos del gabinete o el ejecutivo colegiado con la figura de un vicepresidente.

De acuerdo con Valadés, la propuesta no implica debilitar el poder del ejecutivo, sino fortalecerlo en el sentido de que pueda contar con el apoyo del congreso. Significa la incorporación de instituciones de origen parlamentario, que adopten instituciones de este sistema, pero preservando la estructura básica del sistema receptor. Es decir, subsiste la matriz presidencial, pero se le agregan algunos mecanismos de control político de oriundez parlamentaria. ${ }^{3}$ Estos mecanismos buscan, por un lado, que la relación entre poderes tienda a la cooperación y no al bloqueo y, por el otro, que el legislativo ejerza sus funciones de control. Se trata de una doble interacción compleja porque, mientras el presidente puede obtener el apoyo del congreso, también es al mismo tiempo vigilado y controlado por este órgano.

En los últimos años, se han estudiado las consecuencias de los gobiernos sin mayoría en los presidencialismos. ${ }^{4}$ Para algunos, uno de sus principales efectos negativos es la parálisis política, que termina por afectar la toma de decisiones; para otros, es más bien una de las expresiones del sistema de pesos y contrapesos que debe operar en estos sistemas.

Si consideramos que la gobernabilidad democrática requiere de la formación de mayorías al interior del congreso para tomar decisiones, cuando el partido político del presidente está en condición de minoría, queda necesariamente supeditado a la formación de coaliciones con la oposición partidista

\footnotetext{
${ }^{3}$ Valadés, Diego, La parlamentarización de los sistemas presidenciales, México, UnAM, 2007.

${ }^{4}$ Mainwaring, Scott y Soberg Shugart, Mathew, "El presidencialismo y los sistemas de partido en América Latina" en La reforma del Estado. Estudios comparados, México, unAM, 1996, pp. 125-176.
} 
para poder ejecutar sus políticas y despejar su agenda. Dado que un buen número de presidencialismos latinoamericanos gobiernan bajo condiciones de gobierno dividido, las coaliciones políticas se han establecido como una práctica que permite alcanzar mayorías. Sin embargo, cabe precisar que han tenido las más diversas consecuencias. Si bien han derivado en patrones de cooperación, también han propiciado crisis e inestabilidad política.

Además del gobierno dividido, otro aspecto que motiva la formación de coaliciones se debe a que algunos sistemas presidencialistas gobiernan con sistemas de partidos que dificultan el proceso de gobierno, como por ejemplo, el multipartidismo. ${ }^{6}$ Si el número de partidos es elevado, habrá como consecuencia una fuerte fragmentación en los órganos de representación política.

De igual forma, resulta determinante la intensidad de la polarización ideológica que hay entre las diferentes fuerzas políticas. No es lo mismo para un mandatario negociar sus propuestas de políticas con muchos partidos que con pocos. Tampoco es igual enfrentar a un sistema de partidos moderado que polarizado. Tanto en el bipartidismo como en el multipartidismo, el ejecutivo requiere necesariamente de las coaliciones para formar consensos. Por el contrario, si un presidente cuenta con el apoyo de un partido dominante, crecen las posibilidades de que se anulen los contrapesos y de que los controles sean laxos. Generalmente, un formato multipartidista tiende a activarlos.

En lo que se refiere a las coaliciones políticas, es necesario distinguir entre una coalición electoral, una coalición parlamentaria y un gobierno de coalición. La primera es una fusión entre dos o más partidos para competir en una elección bajo una candidatura común. La segunda se refiere a las alianzas que llevan a cabo las fracciones partidistas en el congreso, con el fin alcanzar la mayoría requerida para aprobar leyes. La tercera implica que el titular del Ejecutivo reparte carteras de gobierno a miembros de la oposición; es una fusión entre partidos políticos para conformar un gabinete bipartidista o multipartidista.

En el caso de la coalición parlamentaria, se recurre a ella generalmente cuando el presidente enfrenta una legislatura controlada por la oposición. Dada la necesidad de formar mayorías, la alianza entre partidos es una alternativa para conseguirlo. Si un presidente decide no coaligarse con otros partidos políticos, quedará en condición de minoría. Pero, si decide hacerlo, tiene dos alternativas. Una es formar una coalición mínima ganadora, esto significa que el partido en el gobierno requiere de algunos votos que le pueden proporcionar legisladores de otro partido, a modo de alcanzar la mayoría requerida para aprobar leyes. La segunda es la coalición sobredimensionada y se conforma por un número mucho más amplio de agrupaciones políticas. ${ }^{5}$

\footnotetext{
${ }^{5}$ Riker, William, "Teoría de juegos y de las coaliciones políticas", en Diez textos básicos de ciencia política, Barcelona, Ariel, 2001, pp. 151-169.
} 
Los sistemas presidenciales con gobierno sin mayoría, que tienden a equilibrar la relación entre ejecutivo y legislativo y fomentan el ejercicio de los contrapesos, tienen como instrumento para evitar una parálisis en la toma de decisiones la formación de coaliciones. Dado el pluralismo de partidos establecido en la mayoría de los países de América Latina, las alianzas se han convertido en una práctica recurrente.

De esta forma, las coaliciones entre partidos políticos tienen varios propósitos: se usan para competir en elecciones, para alcanzar mayorías al interior del Legislativo, así como para formar un gobierno. Algunas experiencias muestran que una coalición entre partidos políticos que compite en elecciones no siempre se traduce en una alianza en el congreso. Mientras los votos reparten los espacios de poder entre partidos, en el congreso deben formalizarse coaliciones con el fin de unir voluntades.

El gobierno de coalición se establece como una alternativa cuando hay ausencia de mayorías congresionales y cuando se pretende formar gabinetes incluyentes. De esta forma, dos órganos claves en el proceso de gobierno (Legislativo y gabinete) no están controlados por un solo partido.

\section{Presidencialismo y gobiernos divididos en México}

Una de las principales características del presidencialismo mexicano durante el siglo Xx fue la concentración de algunos poderes que le permitieron anular los contrapesos del Legislativo y el Judicial, así como controlar verticalmente a los gobernadores y a su partido político. ${ }^{6}$

Por un lado, el presidencialismo tuvo el respaldo de su organización partidista, la cual se caracterizó por una hegemonía electoral que mantuvo durante décadas y por la cohesión y disciplina de sus militantes. ${ }^{7}$ Por otro lado, articuló una estructura corporativa que organizó a las masas de trabajadores en sindicatos, para reproducir las redes de lealtad hacia el gobierno. ${ }^{8}$ Hasta finales del siglo pasado, dio inicio un proceso de transición hacia la democracia, que motivó un conjunto de reformas constitucionales y a ley secundaria, destinadas a modificar algunas instituciones y reglas del régimen político mexicano. Estos cambios tuvieron como objetivo un rediseño del sistema electoral y una nueva composición de los órganos de representación política, tanto en nivel nacional como subnacional.

Desde 1997, se produjo un cambio en la relación de los poderes Ejecutivo y Legislativo. El partido que desde entonces ha controlado el gobierno no ha alcanzado la mayoría absoluta en la Cámara de Diputados, ni desde 2000,

\footnotetext{
${ }^{6}$ Carpizo, Jorge, El presidencialismo mexicano, México, Siglo XXI, 1978.

${ }^{7}$ Mirón, Rosa María, El PRI y la transición politica en México, México, unAm - Gernika, 2001.

${ }^{8}$ Córdova, Arnaldo, La formación del poder político en México, México, Era, 1972.
} 
en el Senado. El establecimiento de gobiernos sin mayoría en México no ha tenido resultados lineales, no siempre se ha producido una parálisis política. Aún con un congreso fragmentado, se han posibilitado los acuerdos.

Ciertamente, se han presentado momentos en donde ha habido bloqueos entre poderes, aunque también se han podido formalizar coaliciones para llegar a acuerdos y tomar decisiones. De este modo, el gobierno dividido en México no siempre ha derivado en desacuerdos, sino también en consensos.

Cuadro 1. Composición del Poder Legislativo en México (1988-1997) (Porcentaje del partido del presidente)

\begin{tabular}{|l|c|c|c|c|}
\hline & \multicolumn{2}{|c|}{ Cámara de Diputados } & \multicolumn{2}{c|}{ Cámara de Senadores } \\
\hline Legislatura & Asientos & $\%$ & Asientos & $\%$ \\
\hline LIV (1988-1991) & 260 & 52 & 60 & 93 \\
\hline LV (1991-1994) & 320 & 64 & 61 & 95 \\
\hline LVI (1994-1997) & 300 & 60 & 95 & 72 \\
\hline
\end{tabular}

En 1988, el número de diputados aumentó a 500 y, en 1994, el de senadores, a 128.

Fuente: Casar, Ma., Amparo, La Cámara de Diputados en el marco de la configuración jurídico Política de la Nación Mexicana, México, CEDIP - Cámara de Diputados, 2014, pp. 283.

Cuadro 2. Composición del Poder Legislativo en México (1997-2018) (Porcentaje del partido del presidente)

\begin{tabular}{|l|c|c|c|c|}
\hline & \multicolumn{2}{|c|}{ Cámara de Diputados } & \multicolumn{2}{c|}{ Cámara de Senadores } \\
\hline Legislatura & Asientos & $\%$ & Asientos & $\%$ \\
\hline LVII (1997-2000) & 239 & 48 & 77 & 60 \\
\hline LVIII (2000-2003) & 206 & 41 & 46 & 36 \\
\hline LIX (2003-2006) & 153 & 31 & 46 & 36 \\
\hline LX (2006-2009) & 206 & 41 & 52 & 41 \\
\hline LXI (2009-2012) & 143 & 29 & 52 & 41 \\
\hline LXII (2012-2015) & 213 & 42 & 52 & 41 \\
\hline LXIII (2015-2018) & 204 & 41 & 55 & 43 \\
\hline
\end{tabular}

Fuente: Idem, pp. 284.

Desde 1997, el porcentaje de representación del partido político del presidente en las dos cámaras del Poder Legislativo no le ha permitido alcanzar ni la mayoría absoluta y, aún menos, la calificada (véase cuadro 2). Esto ha llevado 
a que el presidente negocie con la oposición sus productos de gobierno, dado que el congreso es quien tiene la última palabra en la toma de decisiones. El aumento del número de jugadores con capacidad de veto ha limitado la influencia presidencial en el proceso legislativo.

Otro aspecto importante que produjo el gobierno sin mayoría fue que el mandatario dejó de ser el principal promotor de las iniciativas de leyes y de reformas. El congreso también comenzó a jugar un papel proactivo en esta materia. De igual forma, durante la etapa en la que el PRI estuvo sobrerrepresentado en ambas cámaras, las iniciativas del ejecutivo se aprobaban casi en su totalidad. Después de 1997, la tasa de aprobación descendió considerablemente. Por lo tanto, la relación entre ambos poderes ha derivado en una presidencia que vio disminuida su influencia en el proceso legislativo. $^{9}$

Cuadro 3. Origen de las iniciativas en el Poder Legislativo

\begin{tabular}{|l|c|c|c|c|c|c|}
\hline & \multicolumn{5}{|c|}{ Legislatura } \\
\hline & LVII & LVIII & LIX & LX & LXI & LXII \\
\hline Ejecutivo & 56 & 86 & 76 & 71 & 55 & 81 \\
\hline Senado & 85 & 362 & 672 & 1235 & 1484 & 1612 \\
\hline Diputados & 468 & 920 & 2695 & 2624 & 3588 & 3194 \\
\hline Comisiones & 43 & 24 & 34 & 56 & 34 & 23 \\
\hline Legis. Loc. & 35 & 97 & 129 & 109 & 107 & 100 \\
\hline Varios & 74 & 154 & 84 & 217 & 68 & 343 \\
\hline $\begin{array}{l}\text { Org. } \\
\text { Gobierno }\end{array}$ & Nd & nd & Nd & nd & 1 & 2 \\
\hline Ciudadanos & Nd & nd & Nd & nd & nd & 2 \\
\hline Total & $\mathbf{7 6 1}$ & $\mathbf{1 6 4 3}$ & $\mathbf{3 6 9 0}$ & $\mathbf{4 3 1 2}$ & $\mathbf{5 3 3 7}$ & $\mathbf{5 3 5 7}$ \\
\hline
\end{tabular}

Fuente: Sistema de Información Legislativa de la Secretaría de Gobernación.

\footnotetext{
${ }^{9}$ Nacif, Benito, "El fin de la presidencia dominante: la confección de leyes en un gobierno dividido", en José Luis Méndez (coord.), Los grandes problemas de México, tomo XIII, Políticas Públicas, México, El Colegio de México, 2010.
} 
Cuadro 4. Iniciativas presentadas por el Poder Ejecutivo y tasas de aprobación en la Cámara de Diputados (1997-2015)

\begin{tabular}{|l|c|l|}
\hline & Iniciativas del Ejecutivo & Otros Iniciadores \\
\hline LVII $(1997-2000)$ & $36(78 \%)$ & $169(18 \%)$ \\
\hline LVIII $(2000-2003)$ & $63(87 \%)$ & $1142(22.5 \%)$ \\
\hline LIX (2003-2006) & $49(63 \%)$ & $2900(13 \%)$ \\
\hline LX (2006-2009) & $42(90 \%)$ & $2827(12 \%)$ \\
\hline LXI (2009-2012) & $32(81 \%)$ & $3703(6 \%)$ \\
\hline LXII $(2012-2015)$ & $52(80 \%)$ & $3425(4.5 \%)$ \\
\hline
\end{tabular}

Fuente: Casar, María, Sistema Político Mexicano, México, Oxford, 2015, pp. 103. El número que aparece entre paréntesis se refiere al porcentaje de iniciativas aprobadas.

Desde 1997, la composición de dos cámaras del Poder Legislativo ha sido invariablemente plural. Ello ha implicado un descenso tanto en el número de iniciativas del presidente como de las tasas de aprobación hacia sus propuestas, sobre todo si se considera que, durante la etapa de gobiernos con mayoría, la aprobación estaba arriba de 90\%. La fragmentación de la representación política y del sistema de partidos, así como un mayor rechazo de las propuestas presidenciales, no siempre han producido una parálisis en la toma de decisiones.

En todo caso, el ejecutivo dejó de ser el principal promotor de leyes, sin que ello implique un descenso en la productividad legislativa o una situación de bloqueo permanente entre poderes. No obstante, ha habido discusiones sobre cómo atenuar los potenciales riesgos del gobierno dividido. Para superar esta situación, se han propuesto medidas como el retorno a la cláusula de gobernabilidad para posibilitar la formación de mayorías sobrerrepresentadas en el Congreso. También se ha sugerido dotar de poderes extraordinarios al Ejecutivo (facultades legislativas, de gobierno y partidarias) para que pueda tomar decisiones con una menor interferencia del congreso y los órganos judiciales.

Jorge Carpizo señalaba que "las propuestas anteriores son por demás erradas, con visos nostálgicos de un pasado autoritario que implica el desconocimiento de la existencia de una sociedad más plural y con mayor presencia en los asuntos públicos. Ante este panorama se propone algo obvio: las coaliciones de gobierno". ${ }^{10}$

La idea de un gobierno plural, compartido y consensual en México ha ganado algunos apoyos. El sistema electoral ha producido en los últimos años una fragmentación en el sistema de partidos y en la representación política.

\footnotetext{
${ }^{10}$ Carpizo, Jorge, "Prólogo", en Tania Pérez, Las coaliciones de gobierno. Una necesidad mexicana, México, UnAM, 2001, p. XIV.
} 
Esto implica que el ejecutivo no puede gobernar y tomar decisiones por sí solo, requiere del apoyo de la oposición partidista. Frente a ello, la reforma política de 2014 modificó el artículo 89 constitucional para otorgarle al presidente un instrumento que pueda dinamizar el proceso político: el gobierno de coalición.

\section{LA REFORMA POLÍTICA DE 2014 Y EL GOBIERNO DE COALICIÓN EN MÉXICO}

En 2012, durante el mandato del presidente Enrique Peña Nieto, el ejecutivo y el conjunto de partidos políticos definieron una agenda de reformas con temas comunes, aunque con diferencias de contenido. El acuerdo se denominó Pacto por México y se trató de una coalición parlamentaria formada por el PRI, el PAN, el PRD, el PVEM, el PT, Nueva Alianza y Movimiento Ciudadano. ${ }^{11}$

En un inicio, se formó una amplia coalición que incluyó prácticamente a todas las fuerzas políticas, quienes aprobaron una serie de modificaciones en materia financiera, de educación, de telecomunicaciones, de transparencia, así como una que regula el endeudamiento de las entidades federativas.

Dos años después, el pacto derivó en una coalición mínima ganadora con la aprobación de la reforma fiscal — votada únicamente por el PRI y el PRD - ; la político-electoral y la energética - también votadas únicamente por el PRI y el PAN- La reforma estableció la posibilidad de que el titular del Ejecutivo pueda formalizar un gobierno de coalición. En el caso de este último, se modificó el artículo 89 constitucional para otorgarle al presidente la posibilidad de concretarlo.

En México, como en muchos países del continente, cada vez es más difícil gobernar con mayorías, de aquí que una tendencia es compartir los espacios de gobierno con la oposición, tanto para tomar decisiones como para ejecutarlas. En términos generales, la figura del gobierno de coalición modifica tres componentes del régimen político asociados con los poderes Ejecutivo y Legislativo:

- Otorga un sustento legal a la formación de coaliciones congresionales por parte de los partidos políticos representados en el Congreso.

- El titular del ejecutivo deberá compartir carteras de gobierno con algunos miembros de la oposición partidista.

- El Poder Legislativo ratificará las propuestas del presidente de la república para los titulares del gabinete y otros órganos públicos.

\footnotetext{
${ }^{11}$ Báez, Adriana, "El pacto por México, primera coalición legislativa estructurada en el sistema presidencial mexicano", en Héctor Zamitiz (coord.), Pacto por México. Agenda legislativa y reformas 2013-2014, México, UNAM, 2014, pp. 23-58.
} 
En caso de concretarse, el gobierno de coalición introduciría matices parlamentarios en el presidencialismo mexicano, pues el congreso podría intervenir para ratificar la mayoría de los nombramientos del gabinete. Desde hace algunos años, autores como Jorge Carpizo, Diego Valadés y Alonso Lujambio sugirieron que sería inevitablemente la ruta hacia su parlamentarización.

A continuación, se presenta un extracto de la iniciativa de reforma al artículo 89 constitucional presentada por el Partido Acción Nacional en la cámara alta. Se trata de una modificación que, en caso de concretarse, incidiría en algunos elementos del presidencialismo mexicano, que hasta entonces se mantenían inalterados.

La experiencia de la pasada elección federal muestra claramente que la democracia mexicana demanda una nueva generación de reformas. Para ello, es urgente redefinir los órganos del Estado y las relaciones de cooperación y control entre ellos, evitando la parálisis legislativa causada por el gobierno dividido. Uno de los argumentos que más se han presentado con los sistemas presidenciales es que un gobierno dividido fomenta el estancamiento y la parálisis en las relaciones entre Ejecutivo y Legislativo. En México hemos vivido gobiernos divididos desde 1997, por lo que es necesario conformar gobiernos de coalición que permitan lograr acuerdos que aseguren la posibilidad de que se pueda aprobar una agenda legislativa común a varios partidos.

La iniciativa busca transitar hacia un sistema presidencialista renovado que permita la construcción de un sistema estable de alianzas. La cuestión principal a resolver es la integración de una mayoría gobernante que permita tanto al Legislativo como al Ejecutivo cooperar en el ámbito de sus responsabilidades. En diversos sistemas presidenciales del continente americano ya están presentes algunos elementos parlamentarios como la incorporación de la figura del jefe de gabinete en Argentina, la vicepresidencia en Brasil, la moción de censura en Uruguay o la ratificación de los ministros por parte del congreso en los Estados Unidos de América.

En virtud de lo anterior, se propone facultar al presidente la república para optar por un gobierno de coalición en caso de no contar con mayoría congresional, por lo que deberá acordar el programa de gobierno y la agenda legislativa con las fuerzas políticas representadas en el Congreso. Así mismo, someterá a la Cámara de Senadores, para que sea este órgano legislativo quien, por mayoría simple, ratifique a cada uno de los secretarios de despacho con la salvedad de los secretarios de Defensa Nacional y Marina, en razón de las importantes atribuciones que ambas dependencias tienen encomendadas en materia de seguridad y soberanía nacional. Así mismo, el secretario de 
Hacienda y Crédito Público será ratificado por la Cámara de Diputados. Independientemente de que el gobierno opte o no por el modelo de coalición, se propone también que el Senado de la República ratifique el nombramiento del Secretario de Relaciones Exteriores.

Así, no solo se pretende evitar la parálisis legislativa y administrativa causada en muchas ocasiones por la presencia de un gobierno dividido, sino permite la participación de alguna o algunas fuerzas derrotadas en la conformación de gobierno. En resumen, la posibilidad de contar con un gobierno plural que asegure la participación de otras fuerzas políticas en las que el Congreso de la Unión conoce de los programas de gobierno y la agenda legislativa, permite un consenso ex ante para el impulso de proyectos legislativos y combate de manera eficaz la parálisis legislativa. ${ }^{12}$

En principio, cabe señalar que la formación de un gobierno de coalición se estableció como optativo, es decir, el presidente podrá eventualmente decidir si utiliza este instrumento. Este aspecto es importante, pues la figura es opcional y no obligatoria. Se ha discutido si el gobierno de coalición debió asentarse como un mandato constitucional, independientemente si el ejecutivo lo desea, o si, por el contrario, debe ser potestativo, aunque el artículo 89 constitucional lo establece sólo como una posibilidad.

El próximo mandatario podrá formalizarlo en el momento que considere conveniente y, también, cuenta con la facultad para disolverlo en el momento que desee. ${ }^{13}$ Con ello, no queda obligado durante todo su mandato a abrir los espacios en el gabinete a la oposición y puede también evitar la ratificación del gabinete por parte del congreso. La conformación y la disolución del gobierno de coalición será una prerrogativa exclusivamente presidencial.

Si bien este mecanismo puede contribuir a la formación de acuerdos entre poderes, se puede presentar un escenario donde el partido político que ocupe la presidencia llegue a coaligarse únicamente con un partido menor. Esto podría ser suficiente para alcanzar la mayoría requerida y dejaría fuera del acuerdo al resto de las fuerzas políticas. Con ello, el ejecutivo requeriría del apoyo de un solo partido o de unos cuantos legisladores para formar una coalición mínima ganadora.

A pesar de que esta posibilidad permitiría tomar decisiones e implementar políticas, corre el riesgo de tergiversar la intención original que motivó el gobierno de coalición, pues marginaría del proceso a otras agrupaciones

\footnotetext{
12 "Iniciativa de reforma al artículo 89 de la Constitución Política de los Estados Unidos Mexicanos", LXII Legislatura, Senado de la República, 24 de septiembre, 2013.

${ }^{13}$ Espinoza, Ricardo, "El estancamiento del presidencialismo mexicano: la relación entre los poderes ejecutivo y legislativo", en Alberto Escamilla y PabloJavier Becerra (coords.), El presidencialismo mexicano durante los gobiernos de la alternancia, México, UAm - Miguel Ángel Porrúa, 2013, p. 44.
} 
políticas. Así, en lugar de fomentar una amplia coalición, la oposición pasaría a obstaculizar la agenda del presidente. El tamaño de la coalición será un aspecto clave para reconocer los niveles de inclusión y la voluntad del ejecutivo para compartir espacios de gobierno. ${ }^{14}$

Una de las implicaciones del gobierno de coalición es que el partido del presidente podrá llevar a cabo una alianza congresional, con al menos otro partido de oposición, para alcanzar la mayoría requerida en el Legislativo y, así, aprobar reformas y sancionar leyes. Si bien las coaliciones al interior del congreso son una práctica que se ha venido desarrollando en México desde hace tres décadas, ${ }^{15}$ con la reforma constitucional al artículo 89 se les ha otorgado un sustento legal.

Otra de las implicaciones que puede tener el gobierno de coalición es que el presidente deberá repartir carteras de gobierno con algunos miembros de los partidos de oposición, a modo de formar un gabinete bipartidista o multipartidista. De esta manera, el ejecutivo, junto con su partido y al menos otra fuerza política, tendrán que definir, de manera conjunta, un programa de gobierno y una agenda legislativa común.

Por lo general, los mandatarios suelen designar secretarios de Estado y funcionarios de la administración pública federal que pertenecen a su partido político. Si este nuevo mecanismo entra en vigor, se pondría fin al gobierno formado por un solo partido. Con ello, las elecciones presidenciales podrían dejar de constituirse en un juego de suma cero, en donde "el ganador se lo lleva todo" y la oposición partidista queda excluida de los espacios de gobierno.

Cabe decir que no sería la primera vez que un mandatario incluiría a militantes de los partidos políticos de la oposición. Durante los sexenios de Ernesto Zedillo (1994-2000), Vicente Fox (2000-206) y Felipe Calderón (2006-2012), se abrieron algunos espacios dentro de la estructura gubernamental. El primero, siendo de filiación priista, concedió la Procuraduría General de la República a Antonio Lozano Gracia, militante del Partido Acción Nacional. El segundo, de afiliación panista, nombró como secretario de Hacienda y Crédito Público a Francisco Gil Díaz, perteneciente al PRI. El tercero, también panista, designó como secretario de Comunicaciones y Transportes a Luis Téllez, y como director general de Petróleos Mexicanos, a Jesús Reyes Heroles, ambos de denominación priista. ${ }^{16}$

\footnotetext{
${ }^{14}$ Morgenstern, Negri y Pérez Liñán, "La oposición parlamentaria en los regímenes presidenciales: el caso latinoamericano", en Luisa Béjar (coord.), ¿Qué pasa con la representación en América Latina? México, unam - Miguel Ángel Porrúa, 2009, pp. 13-50.

${ }^{15}$ Desde que el PRI perdió por primera vez la mayoría calificada en la Cámara de Diputados en 1988, las coaliciones en el congreso han sido necesarias, no sólo para sancionar leyes y reformas, sino también para aprobar el presupuesto.

${ }^{16}$ Pérez Farca, Tania, Las coaliciones de gobierno. Una necesidad mexicana, México, unam - Porrúa, 2011.
} 
Si el próximo presidente opta por el gobierno de coalición, la mayoría de los titulares del gabinete deberán ser ratificados por el Poder Legislativo. Esto significa que el titular del Ejecutivo perdería la facultad exclusiva para designar a sus ministros. La reforma al artículo 89 constitucional mantiene la facultad del Senado para ratificar al secretario de Relaciones Exteriores y al fiscal general de la república, quien sustituirá al procurador, a partir de 2018. La Cámara de Diputados lo hará ahora con el secretario de Hacienda. Sin embargo, si se concreta el gobierno de coalición, el conjunto de los nombramientos de los secretarios de Estado deberán ser ratificados por la Cámara baja por mayoría simple. Las excepciones serían los titulares de las Secretarías de Defensa y de Marina, quienes serán nombrados de manera exclusiva por el presidente.

El dictamen final del artículo 89 constitucional aprobado en el Senado quedó de la siguiente forma. En la fracción XVII se establece que el presidente de la república "En cualquier momento podrá optar por un gobierno de coalición con uno o varios de los partidos políticos representados en el Congreso de la Unión. El gobierno de coalición se regulara por el convenio y programa respectivos, los cuales deberán ser aprobados por la mayoría de los miembros presentes de la Cámara de Senadores. El convenio establecerá también las causas de la disolución del gobierno de coalición."

A su vez, la fracción IX faculta a la Cámara de Senadores para "Intervenir en la designación del Fiscal General de la República y removerlo en términos de lo dispuesto en el artículo 102 apartado A". La fracción II asienta que "En los supuestos de la ratificación de los Secretarios de Relaciones Exteriores y de Hacienda, cuando no se opte por un gobierno de coalición, si la cámara respectiva no ratificara en dos ocasiones el nombramiento del mismo Secretario de Estado, ocupará el cargo la persona que designe el Presidente de la República". ${ }^{17}$

Con este fundamento constitucional, entraría en vigor el gobierno de coalición en México. No obstante, hasta mediados del año 2017, no se ha elaborado ninguna ley secundaria que precise el procedimiento para su posible conformación y disolución.

En los presidencialismos en la región latinoamericana, el ejecutivo cumple con varios papeles: es jefe de Estado, jefe de Gobierno, jefe de partido y colegislador. Dentro de sus múltiples prerrogativas, dos de las más importantes son los poderes de gobierno y los legislativos. Los primeros le sirven para "nombrar y remover a los ministros del gabinete, así como a los altos

\footnotetext{
17 "Proyecto de Decreto por el que se adicionan y derogan diversas disposiciones de la Constitución Política de los Estados Unidos Mexicanos en materia político electoral”, 13 de mayo de 2014.
} 
funcionarios administrativos y judiciales"; los segundos son "para participar e influir en la elaboración de políticas legislativas". ${ }^{18}$

Si bien la facultad que tuvieron los mandatarios para nombrar a la mayoría de los miembros de su gabinete era exclusiva, las reformas políticas en varios países han permitido gradualmente la incorporación del Poder Legislativo para ratificar las propuestas presidenciales. La tendencia indica una participación cada vez más constante del congreso en esta materia.

El siguiente cuadro muestra los métodos para designar a los titulares de los gabinetes en los diferentes países latinoamericanos. El caso mexicano sería el primero en introducir la ratificación del Poder Legislativo para la mayoría de las propuestas de los secretarios de Estado y titulares de otros organismos públicos. En todos los casos, los poderes de nombramiento de los presidentes siguen siendo amplios, salvo ciertos funcionarios, ya sean ministros o titulares de órganos autónomos.

Cuadro 5. Designación y remoción del gabinete presidencial en América Latina

\begin{tabular}{|c|c|}
\hline País & Designación \\
\hline Argentina & Designación y remoción libres por el presidente. \\
\hline Bolivia & $\begin{array}{l}\text { Designación y remoción libres por el presidente, excepto el con- } \\
\text { tralor general del Estado, el presidente del Banco Central, las } \\
\text { autoridades del Órgano de Regulación de Bancos y Entidades } \\
\text { Financieras, así como a los presidentes de entidades de Función } \\
\text { Económica y Social (nombrados por la Asamblea Nacional } \\
\text { Plurinacional). }\end{array}$ \\
\hline Brasil & $\begin{array}{l}\text { Designación y remoción libres por el presidente, excepto los } \\
\text { ministros del Supremo Tribunal Federal y de los Tribunales } \\
\text { Superiores, los gobernadores de Territorios, el procurador general } \\
\text { de la república, el presidente y los directores del Banco Cientral } \\
\text { (aprobados por el Senado Nacional). }\end{array}$ \\
\hline Chile & $\begin{array}{l}\text { Designación y remoción libres por el presidente, excepto el fiscal } \\
\text { nacional (designado por el Senado). }\end{array}$ \\
\hline Colombia & $\begin{array}{l}\text { Designación y remoción libres por el presidente, excepto el pro- } \\
\text { curador general de la nacional (electo por el Senado). }\end{array}$ \\
\hline Costa Rica & Designación y remoción libres por el presidente. \\
\hline Ecuador & $\begin{array}{l}\text { Designación y remoción libres por el presidente, excepto el procu- } \\
\text { rador general del Estado y el fiscal general del Estado (posesionados } \\
\text { por la Asamblea Nacional). }\end{array}$ \\
\hline
\end{tabular}

${ }^{18}$ Negretto, Gabriel, La política del cambio constitucional en América Latina, México, FCE, 2015. 


\begin{tabular}{|c|c|}
\hline El Salvador & $\begin{array}{l}\text { Designación y remoción libres por el presidente, excepto el fiscal } \\
\text { general de la república y el procurador general de la república } \\
\text { (electo por la Asamblea Legislativa). }\end{array}$ \\
\hline Guatemala & Designación y remoción libres por el presidente. \\
\hline Honduras & $\begin{array}{l}\text { Designación y remoción libres por el presidente, excepto los } \\
\text { miembros del Tribunal Superior de Cuentas, el procurador y el } \\
\text { subprocurador general de la república, el fiscal general de la repú- } \\
\text { blica y el fiscal general adjunto, el procurador y el subprocurador } \\
\text { del Ambiente (electos y removidos por el Congreso Nacional). }\end{array}$ \\
\hline México & $\begin{array}{l}\text { Designación y remoción libres por el presidente, excepto el secre- } \\
\text { tario de Hacienda (ratificación por la Cámara de Diputados), el } \\
\text { secretario de Relaciones Exteriores, el fiscal general de la república, } \\
\text { altos mandos del Ejército, de la Armada y de la Fuerza Aérea } \\
\text { nacionales (ratificados por la Cámara de Senadores). En caso } \\
\text { de que el ejecutivo opte por el gobierno de coalición, la Cámara } \\
\text { de Diputados ratificará al resto de los titulares del gabinete con } \\
\text { excepción de los secretarios de Defensa y de Marina. }\end{array}$ \\
\hline Nicaragua & $\begin{array}{l}\text { Designación y remoción libres por el presidente, excepto el fiscal } \\
\text { general de la república (electo por la Asamblea Nacional). }\end{array}$ \\
\hline Panamá & Designación y remoción libres por el presidente. \\
\hline Paraguay & Designación y remoción libres por el presidente. \\
\hline Perú & $\begin{array}{l}\text { Designación y remoción libres por el presidente de la república } \\
\text { y por el presidente del Consejo de Ministros (son nombrados y } \\
\text { removidos a propuesta del presidente del Consejo). }\end{array}$ \\
\hline $\begin{array}{l}\text { República } \\
\text { Dominicana }\end{array}$ & Designación y remoción libres por el presidente. \\
\hline Uruguay & $\begin{array}{l}\text { Designación y remoción libre por el presidente (con apoyo } \\
\text { parlamentario). }\end{array}$ \\
\hline Venezuela & $\begin{array}{l}\text { Designación y remoción libres por el presidente, excepto del procu- } \\
\text { rador general de la república (ratificado por la Asamblea Nacional). }\end{array}$ \\
\hline
\end{tabular}

Fuente: elaboración propia con datos de las constituciones políticas de los países latinoamericanos.

Los ocho países que mantienen los poderes de nombramiento del gabinete como una facultad exclusiva presidencial son Argentina, Costa Rica, Guatemala, Panamá, Paraguay, Perú, República Dominicana y Uruguay. En el caso de Perú, interviene también el presidente del Consejo de Ministros, órgano que pertenece al Ejecutivo. Aquellos países donde la designación de algunos ministros y titulares de los órganos autónomos recae en las cámaras del Poder Legislativo son siete: Bolivia, Chile, Colombia Ecuador, El Salvador, Honduras y Nicaragua. En tres casos, Brasil, México y Venezuela, el Legislativo participa sólo para ratificar. 
En muchos países, la intervención de los órganos legislativos en el nombramiento de los ministros todavía es limitada, aunque ya tienen mayor participación para nombrar y aprobar a procuradores, fiscales y titulares de los órganos autónomos. Por último, cabe apuntar que Argentina y Ecuador han recurrido a los gobiernos de coalición en dos ocasiones, Uruguay lo ha hecho tres veces; Bolivia y Colombia, en cinco; Chile, en seis y Brasil, en siete. ${ }^{19}$

De esta forma, la propuesta del gobierno de coalición en México introduce matices parlamentarios en el sistema presidencialista. En Argentina ya estaba la figura del jefe de gabinete; en Brasil, la del vicepresidente. En Uruguay, el Legislativo puede aplicar una moción de censura a los ministros y, en México, eventualmente podrían ser ratificados la mayoría de los secretarios de Estado. Sin embargo, la incorporación de estos matices todavía no es una tendencia en la región.

\section{CONCLUSIONES}

La formación de un gobierno de coalición en México queda abierta como una posibilidad después de las elecciones presidenciales de 2018, una vez que la reforma al artículo 89 constitucional lo permite. La figura se presenta como una vía para atenuar los efectos del gobierno dividido y como un instrumento que puede fomentar tanto la cooperación como los controles entre los poderes Ejecutivo y Legislativo. El mandatario tendrá la potestad para formalizarla y disolverla en cualquier momento.

Las tres características que definen esta figura son las alianzas entre partidos políticos al interior del congreso, para formar mayorías; la repartición de carteras de gobierno por parte del presidente, con algunos militantes de la oposición, y la ratificación de la mayoría de los titulares del gabinete por parte del Poder Legislativo.

Si bien la reforma constitucional fue aprobada en 2014, hasta 2017 no se ha elaborado una ley secundaria que especifique las modalidades para su formación y disolución. Tampoco se han detallado los procedimientos con los que operaría. En caso de implementarse, pueden presentarse tres escenarios para el próximo presidente: uno, que su partido político obtenga los escaños necesarios en el congreso para alcanzar una mayoría absoluta; segundo, encabezar un gobierno en condición de minoría; tercero, formar un gobierno de coalición.

Si bien el gobierno de coalición puede resolver algunos problemas derivados de la separación de poderes, también conlleva algunos riesgos. Por ejemplo, el presidente y su partido político pueden llevar a cabo un acuerdo

\footnotetext{
${ }^{19}$ Albala, Adrián, "Presidencialismo y Coaliciones de Gobierno en América Latína: Un Análisis del Papel de las Instituciones", Revista de Ciencia Política, vol. 36, núm. 2, pp. 459-479.
} 
únicamente con otra fuerza política con menor presencia electoral. Con ello, formarían una coalición mínima ganadora, lo cual implicaría que la mayoría de las fuerzas políticas quedarían fuera del acuerdo.

Si bien algunas experiencias han resultado exitosas en el sentido de que los ejecutivos han obtenido el apoyo de la oposición para generar consensos, aprobar leyes, implementar políticas públicas y despejar la agenda, también pueden resultar contraproducentes. La oposición podría abandonar en cualquier momento la coalición - situación que ocurre con frecuencia- y dejar al ejecutivo en condición de minoría. Con ello, se podría generar una dinámica de confrontación que terminaría por romper la coalición y producir un enfrentamiento entre la clase política.

Un ejemplo de gobierno de coalición con consecuencias negativas tuvo lugar en Brasil, durante el año 2016, cuando la presidenta Dilma Rousseff abrió espacios en la estructura gubernamental a los partidos de oposición. Una cartera que entregó fue la vicepresidencia. Al interior de la alianza, se produjo una división y una ruptura. La intensidad del conflicto ocasionó que el congreso rompiera lazos con el gobierno y llevara a cabo un juicio político contra la mandataria.

El caso de Brasil muestra que un gobierno de coalición puede derivar en una confrontación entre poderes e incluso terminar en la aplicación de un impeachment (proceso de destitución) contra el ejecutivo. También, cabe considerar que, si un presidente obtiene el apoyo del conjunto de partidos, tendería a reforzar su poder. De este modo, podrían aprobarse las políticas de su preferencia, lo cual llevaría a atenuar los contrapesos y los controles políticos hacia sus acciones.

Un gobierno de coalición, de inicio, puede propiciar apoyos y acuerdos entre partidos políticos y poderes públicos. Sin embargo, esto no significa que así será mientras la alianza perdure. También pueden producirse desencuentros que terminan desestabilizando al régimen.

Para el caso de México, la posible adopción de un gobierno de coalición tendría implicaciones directas en el presidencialismo, pues se introducirían matices parlamentarios. Primero, las alianzas entre partidos políticos al interior del congreso podrían constituirse en un instrumento de cooperación entre poderes, frente al pluralismo de partidos. La ruta de las coaliciones sería una alternativa para contrarrestar los efectos negativos de la ausencia de mayorías congresionales. Segundo, la repartición de carteras de gobierno con la oposición resultaría algo novedoso.

Los resultados, por ahora, son inciertos pues dependerá del comportamiento de los partidos, tanto en la definición como en la ejecución de políticas. Por último, la ratificación de la mayoría de los miembros del gabinete por parte de las cámaras sería un procedimiento nuevo, pues le otorgaría al congreso mayores instrumentos de control. En tal caso, el Ejecutivo propondría los nombramientos y el Legislativo deberá aprobarlos. 
La reforma constitucional al artículo 89 tienen dos direcciones opuestas, los acuerdos al interior del legislativo pueden terminar por reforzar la capacidad del presidente para crear leyes y definir políticas, mientras que la apertura del gabinete hacia la oposición partidista, así como la ratificación de sus titulares limitaría sus facultades de nombramiento y su discrecionalidad para formar un gobierno.

Con esta reforma, el Legislativo puede tener un comportamiento cooperativo y reforzar sus instrumentos de control hacia los poderes de nombramiento del Ejecutivo. Las dos funciones son complementarias, dado que apoyan y controlan, al mismo tiempo, las propuestas del presidente. La primera puede agilizar el proceso legislativo, mientras la segunda propicia que el presidente ya no designe a su gabinete; ahora, sólo propondría.

De igual forma, el gobierno de coalición evitaría la formación de un gobierno compuesto por un solo partido. De esta forma, el ejecutivo no sólo enfrentaría un congreso multipartidista, sino que también contaría con ministros de diferentes denominaciones partidistas. Dos piezas relevantes en el proceso legislativo y de gobierno ya no estarían controladas por el mismo partido.

Si bien el multipartidismo en el congreso ya era parte de la realidad política en México, la formación de un gabinete plural, así como su ratificación, resultaría una experiencia novedosa para la política mexicana. Esto no necesariamente produciría una fusión de poderes, como ocurre en los sistemas parlamentarios, sino que únicamente se conformaría un gobierno compartido, tanto para definir como para ejecutar políticas.

\section{B I B L I OGRAF Í A}

Albala, Adrián, (2016), "Presidencialismo y Coaliciones de Gobierno en América Latína: Un Análisis del Papel de las Instituciones", en Revista de Ciencia Política, vol. 36, núm. 2, Santiago de Chile, pp. 459-479.

Báez, Adriana, (2014), "El pacto por México, primera coalición legislativa estructurada en el sistema presidencial mexicano" en Héctor Zamitiz (coord.), Pacto por México. Agenda legislativa y reformas 2013-2014, nam, México, pp. 23-58.

Béjar, Luisa, (2010), "De la Centralización a la Descentralización. El nuevo diseño institucional del Congreso de la Unión”, Foro Internacional, vol. L, núm. 1, Colegio de México, México, pp. 115-143.

Bovero, Michelangelo, (2001), "Sobre el presidencialismo y otras malas ideas. Reflexiones a partir de la experiencia italiana" en Miguel Carbonell, Hugo Concha, Lorenzo Córdova y Diego Valadés (coords.), Estrategias y propuestas para la reforma del Estado, UNAM/IIJ, México, pp. 15-24.

Carpizo, Jorge, (1978), El presidencialismo mexicano, Siglo XXI, México, 240 pp. , (2011), "Prólogo", en Pérez, Tania, Las coaliciones de gobierno. Una necesidad mexicana, UNAM, México, pp. 13-17.

Casar, Ma. Amparo, (2014), La Cámara de Diputados en el marco de la configuración jurídico Política de la Nación Mexicana, CEDip/ Cámara de Diputados, México, 332 pp. 
, (2015), Sistema Político Mexicano, Oxford, México, 292 pp.

Colomer, Josep, (2001), Instituciones políticas, Ariel, Barcelona, 267 pp.

Colomer, Josep y Gabriel Negretto (2003), "Gobernanza con poderes divididos en América Latina” en Política y Gobierno, vol. X, núm 1, cide, México, pp. 13-61.

Córdova, Arnaldo, (1972), La formación del poder político en México, Era, México, 99 pp.

Espinoza, Ricardo, (2013), "El estancamiento del presidencialismo mexicano: la relación entre los poderes ejecutivo y legislativo" en Alberto Escamilla y Pablo Javier Becerra (coords.), El presidencialismo mexicano durante los gobiernos de la alternancia, una/Miguel Ángel Porrúa, México, pp. 33-54.

Jiménez, Margarita, (2006), La oposición parlamentaria en México. Su rendimiento en gobiernos de mayoría dividida, Miguel Ángel Porrúa, México, 365 pp.

Lanzaro, Jorge, (2001), "Tipos de presidencialismo y modos de gobierno en América Latina" en Jorge Lanzaro (comp.), Tipos de presidencialismo y coaliciones políticas en América Latina, Clacso, Buenos Aires, pp 15-40.

Lijphart, Arend, (2000), Modelos de Democracia, Ariel, Barcelona, 315 pp.

Linz, Juan, (1994), "Democracia presidencial o parlamentaria ¿qué diferencia implica?" en Juan Linz y Arturo Valenzuela (comps.), Las crisis del presidencialismo, tomo 1, Perspectivas comparadas, Ariel, Madrid, pp. 25-143.

Mainwaring, Scott y Mathew Soberg Shugart, (1996), "El presidencialismo y los sistemas de partido en América Latina" en La reforma del Estado. Estudios comparados, UnaM, México, pp. 125-176.

Mirón, Rosa María, (2011), El PRI y la transición política en México, unam/Gernika, México, 415 pp.

Morgenstern, Negri y Pérez Liñán (2009), "La oposición parlamentaria en los regímenes presidenciales: el caso latinoamericano", en Luisa Béjar (coord.), ¿Qué pasa con la representación en América Latina? UnAm/Miguel Ángel Porrúa, México, pp. 13-50.

Nacif, Benito, (2010), "El fin de la presidencia dominante: la confección de leyes en un gobierno dividido" en José Luis Méndez (coord.), Los grandes problemas de México, tomo XIII, Políticas Públicas, El Colegio de México, México, pp. 45-83.

Negretto, Gabriel, (2015), La política del cambio constitucional en América Latina, FCE, México, 364 pp.

Nohlen, Dieter, (1998),"Presidencialismo versus parlamentarismo: dos enfoques contrapuestos" en Dieter Nohlen y Mario Fernández (ed.), El presidencialismo renovado. Instituciones y cambio político en América Latina, Nueva Sociedad, Venezuela, pp. 15-25.

Pérez Farca, Tania, (2011), Las coaliciones de gobierno. Una necesidad mexicana, UNAM/Ed. Porrúa, México, 203 pp.

Pasquino, Gianfranco, (2004), Sistemas politicos comparados, Prometeo, Buenos Aires, $218 \mathrm{pp}$.

Riker, William, (2001), "Teoría de juegos y de las coaliciones políticas" en Diez textos básicos de ciencia política, Ariel, Barcelona, pp. 151-169.

Sartori, Giovanni, (1996), Ingeniería constitucional comparada. Una investigación de estructuras, incentivos y resultados, FCE, México, segunda reimpresión, 227 pp.

Valadés, Diego, (2007), La parlamentarización de los sistemas presidenciales, UNAM/IIJ, México, $255 \mathrm{pp}$.

, (2005), El Gobierno de gabinete, UNAm/IIJ, México, 170 pp. 


\section{Documentos oficiales}

Iniciativa de reforma al artículo 89 de la Constitución Política de los Estados Unidos Mexicano, LXII Legislatura, Senado de la República, 24 de Septiembre de 2013.

Proyecto de Decreto por el que se adicionan y derogan diversas disposiciones de la Constitución Política de los Estados Unidos Mexicanos en materia político electoral; 13 de Mayo de 2014. 